\title{
Study of Carbon Black, Nitrogen and Sulphur Codoped Graphite and Graphene-Like Sheets Supported NiCo Alloy Catalyst for Hydrazine Electrooxidation in Alkaline Media
}

\author{
Jingyi Zhang, Jianshu Li, Chengde Huang ${ }^{*}$ \\ Department of Applied Chemistry, School of Chemical Engineering and Technology, \\ Tianjin University, Tianjin, 300072, PR China \\ *E-mail: cdhuang@tju.edu.cn
}

doi: $10.20964 / 2018.02 .09$

Received: 19 June 2017 / Accepted: 23 November 2017 / Published: 28 December 2017

\begin{abstract}
In this work, three different types of carriers were used: VULCAN XC-72 conductive carbon black, nitrogen and sulphur codoped graphite (NSG) and the graphene-like sheets adsorbed sodium salt of flavin mononucleotide (FMNSC). Catalysts with three kinds of carriers supporting Ni and four Ni-Co alloy catalysts with different $\mathrm{Ni}$-Co ratios were prepared by a simple chemical reduction method. Next, the catalytic process and performance for hydrazine electrooxidation in alkaline media were studied. The structure and morphology of the obtained Ni and Ni-Co alloy catalysts were characterized by Xray diffraction (XRD), energy dispersive spectrometry (EDS) and X-ray photoelectron spectroscopy (XPS). The electrocatalytic performance of the catalysts toward hydrazine electrooxidation was investigated by cyclic voltammetry (CV), chronoamperometry (CA) and electrochemical impedance spectroscopy (EIS) methods. The results show that the catalytic performance of FMNSG supported $\mathrm{NiCo}$ with four different ratios is better than that for the conductive carbon black and nitrogen and sulphur codoped graphite. Otherwise, the catalytic performance of $\mathrm{Ni}_{8} \mathrm{Co}_{2}$ alloy catalyst is better than that of the catalysts with other Ni-Co ratios. This finding suggests that the catalytic performance can be improved by adding an appropriate proportion of Co atoms. The EIS results show that electron transfer processes present on the surface and the impedance of preliminary and secondary oxidation is also lower than for other catalysts, showing high catalytic activity. The analysis results of XPS indicate that the high amount of $\mathrm{Ni}^{2+}$ and $\mathrm{Co}^{2+}$ existed on the catalysts may be improve the rate of intermediate $\left(\left[\mathrm{HO}-\mathrm{H}_{2} \mathrm{~N}=\mathrm{NH}_{2}-\mathrm{OH}\right]^{2-}\right)$ formation and rate-limiting step, thereby can enhance the electrocatalytic activity.
\end{abstract}

Keywords: hydrazine electrooxidation, Ni-Co alloy, support, graphene-like sheets, modified $\underline{\text { FULL TEXT }}$ 
(C) 2018 The Authors. Published by ESG (www.electrochemsci.org). This article is an open access article distributed under the terms and conditions of the Creative Commons Attribution license (http://creativecommons.org/licenses/by/4.0/). 